\title{
Primeiro registro de Myrothecium roridum em noni no Brasil
}

\section{Luiz Sebastião Poltronieri ${ }^{1}$, Francisco das Chagas de Oliveira Freire², Jaqueline Rosemeire Verzignassi ${ }^{3}$, Tathianne Pastana de Sousa Ferreira ${ }^{4}$, Ana Carla de Andrade Costa Souza ${ }^{4}$}

\begin{abstract}
${ }^{1}$ Amazônia Oriental, Tv. Enéas Pinheiro, S/N, CEP 66095-100, Belém, PA, e-mail: poltroni@cpatu.embrapa.br. ${ }^{2}$ Embrapa Agroindústria Tropical, Rua Dra. Sara Mesquita, 2270, Planalto do Pici, CEP 60511-110, Fortaleza, CE. ${ }^{2}$ Embrapa Gado de Corte, Rod. BR 262, Km 4, Caixa Postal 154, CEP 79002-970, Campo Grande, MS. ㄴniversidade Federal Rural da Amazônia, Av. Perimetral, 2501, CEP 66077-530, Caixa Postal 917, Belém, PA. Autor para Correspondência: Luiz S. Poltronierie-mail: poltroni@cpatu.embrapa.br.
\end{abstract}

Data de chegada: 20/12/2007. Aceito para publicação em: 23/09/2008

O noni (Morinda citrifolia L.), planta da família das rubiáceas, é nativa do Sudeste da Ásia e produz frutos de importantes propriedades nutricionais e nutracêuticas. Há mais de 2000 anos os frutos são utilizados na Polinésia, China, Índia e, nos últimos anos, o cultivo foi iniciado também no Brasil. Mudas de noni, em pomar do campo experimental da Embrapa Amazônia Oriental (Belém, PA), apresentaram manchas foliares concêntricas castanho-claras, variando de $0,5 \mathrm{~cm}$ a $0,8 \mathrm{~cm}$ de diâmetro e dispersas pelo limbo foliar. $\mathrm{O}$ isolamento foi efetuado em BDA $\left(26^{\circ} \mathrm{C}\right.$ e luz fluorescente, com fotoperíodo de $12 \mathrm{~h}$ ) e, aos três dias, foram observadas colônias de coloração branca. Observações ao microscópio óptico permitiram a identificação do fungo Myrothecium roridum Tode ex Fr. O fungo forma esporodóquios, algumas vezes sinematosos, com até $700 \mathrm{~mm}$ de diâmetro. Os conídios são formados em uma massa achatada, com aspecto úmido, de coloração negra e brilhante. A esporulação ocorre, freqüentemente, em círculos concêntricos. Os conídios apresentavam forma de bastões, às vezes elipsóides, com as extremidades comumente arredondadas, hialinos a levemente oliváceos, freqüentemente exibindo gotículas e medindo de 4,5 - 7,3 mm x 1,5 a $2 \mathrm{~mm}$. Testes de patogenicidade foram efetuados em folhas e frutos destacados previamente feridos, inoculados com discos de cultura contendo estruturas do fitopatógeno e submetidos à câmara úmida por $48 \mathrm{~h}$. Após cinco dias, as folhas e os frutos apresentaram os mesmos sintomas encontrados no campo, dos quais efetuou-se o reisolamento do fungo, confirmando-se a sua patogenicidade. $M$. roridum foi detectado, anteriormente, no Pará, em juta (Corchorus capsularis L.) e acerola (Malpighia glabra L.). O isolado de noni foi inoculado em outras espécies de plantas citadas na literatura como hospedeiras de Myrothecium spp., seguindo-se a mesma metodologia utilizada para o teste de patogenicidade, a saber: café arábica (Coffea arabica L.), juta, soja (Glycine max (L.) Merr.), arroz (Oryza sativa L.), feijão (Phaseolus vulgaris L.), caupi (Vigna unguiculata L. Walp.), acerola, tomateiro

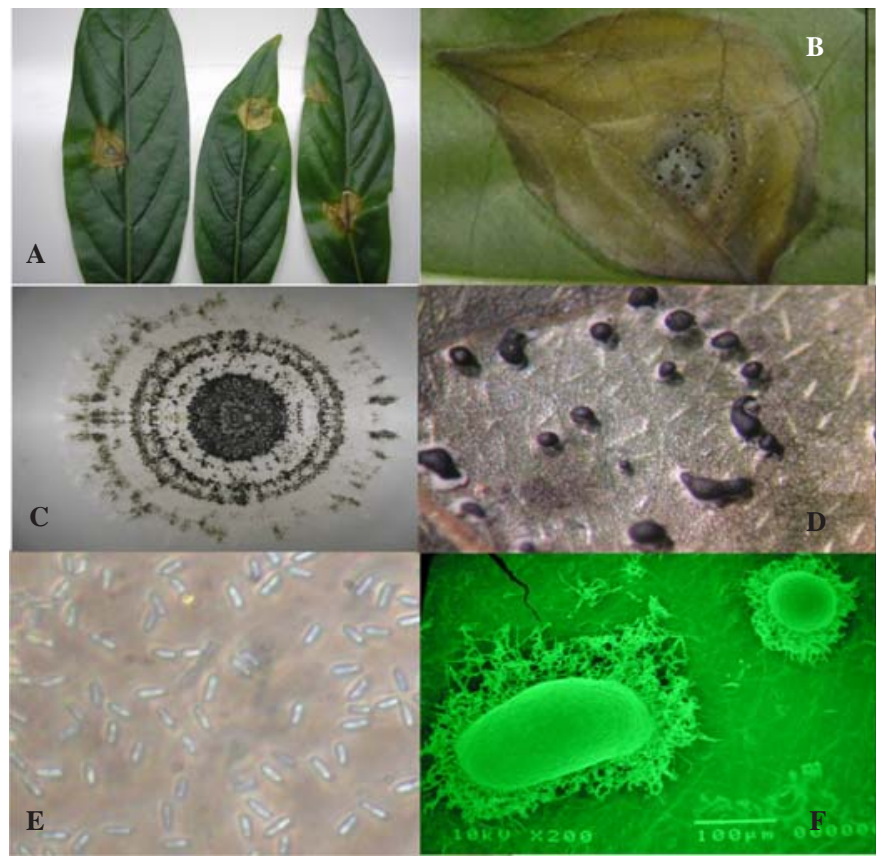

Figura 1. A e B) Folhas de noni apresentando sintomas causados por Myrothecium roridum; C e D) Colônias de $M$. roridum em meio de BDA; E e F) Conídios de M. roridum ao MO (E) e ao MEV (F).

(Solanum lycopersicum L.), algodoeiro (Gossypium sp. L.), tanchagem (Plantago major L.), grama-amendoim (Arachis repens Handro) e meloeiro (Cucumis melo L.). Com exceção ao meloeiro, todas as outras espécies de plantas foram suscetíveis, evidenciando a inespecificidade do isolado ao noni. Este é o primeiro registro de Myrothecium roridum afetando plantas de noni no Brasil e, provavelmente, no mundo. 